\title{
PESSOAS QUE VIVEM SÓS: QUEM SÃO ELAS NAS OITO MAIORES CAPITAIS BRASILEIRAS
}

\author{
SINGLES IN THE EIGHT BIGGEST CAPITAL \\ CITIES IN BRAZIL: WHO THEY ARE
}

Recebido - 20/09/2010

Aceito - 14/07/2011

\section{Adriana Beatriz Madeira ${ }^{1}$ e José Augusto Giesbrecht da Silveira ${ }^{2}$}

\begin{abstract}
Resumo
O Brasil apresenta uma das dez maiores taxas de participação de indivíduos que vivem sós em relação ao total da população, sendo que eles somam cerca de $10 \%$ dos habitantes do país. Este estudo se baseia nos microdados dos censos demográficos de 1970, 1980, 1991 e 2000, e objetiva apresentar a caracterização dos grupos pelos quais se subdivide este segmento da população e descortinar tendências gerais. Nas oito maiores capitais brasileiras, em termos populacionais, este segmento apresenta uma composição bastante variada com relação a sexo, idade, renda, alfabetização, aposentadoria e posse de domicílio, tanto em uma mesma cidade, ao longo do tempo, como entre cidades, em um mesmo instante de tempo. Embora a diversidade seja a regra geral na composição do segmento, o estudo identifica e apresenta algumas tendências amplas: o segmento cresce mais rapidamente que o aumento da população em geral; está havendo um aumento da idade média das pessoas que o compõem (envelhecimento); há predominância de mulheres; e em matéria de rendimentos, há maior incidência de rendas mais baixas e mais altas que de rendas médias. É importante considerar o número de pessoas que vivem sozinhas e sua caracterização sociodemográfica quando se abordam questões ligadas a consumo, produção de bens e serviços e seus desdobramentos.
\end{abstract}

Palavras-chave: Pessoas que moram sós. Segmentação de mercado. Características sociodemográficas. Capitais brasileiras.

\footnotetext{
1 Professora Doutora do Departamento de Administração do Centro de Ciências Sociais e Aplicadas da Universidade Presbiteriana Mackenzie. E-mail: adri.madeira@mackenzie.br; adri.madeira@usp.br

2 Professor Doutor do Departamento de Administração da Faculdade de Economia, Administração e Contabilidade da Universidade de São Paulo. E-mail: jags@usp.br
} 


\begin{abstract}
Brazil is in the global top ten in terms of the percentage of individuals who live alone in relation to the rest of the population; they make up some $10 \%$ of the country's total population. This study, based on micro data from the demographic censuses of 1970, 1980, 1991, and 2000 and aims to characterize the groups into which this segment is divided and uncover general trends. In the eight largest Brazilian capitals, this segment ranges widely in gender, age, income, literacy, and home ownership, whether in the same city over a period of time, or among different cities at the same instant of time. Although diversity is the general rule in the composition of this segment, this study identifies and presents a few broad tendencies: this segment grows at a faster pace than the increase in population in general; there is an increase in the average age of the people composing it (aging); women predominate; and there are more low and high incomes than median incomes. It is important to consider the number of people that live alone and their socio-demographic characterization when addressing issues related to the consumption and production of goods and services and their ramifications. capital cities.

Keywords: People who live alone. Market segmentation. Socio-demographic characteristics. Brazilian
\end{abstract}

\title{
1 INTRODUÇÃO
}

Estatísticas demográficas muito genéricas podem mascarar implicações importantes sobre o consumo. Por exemplo, quando se considera apenas o crescimento da população total e não um eventual crescimento do número de domicílios, superior ao da população como um todo, perde-se um componente que faz o consumo ou a demanda aumentar mais que, proporcionalmente, o mero crescimento populacional. Isto acontece pois há bens e serviços para os quais o consumidor não é a pessoa, mas o domicílio. Como ilustração, um refrigerador não é demandado por uma pessoa, mas pelo domicílio no qual ela habita. No Brasil, o número de domicílios tem crescido mais rapidamente que a população em geral e, além disso, o número de domicílios habitados por um único morador tem-se expandido mais depressa que o número de moradias.

O Brasil faz parte dos dez países que apresentam as maiores taxas de participação de indivíduos que vivem sós em relação ao total da população (LIU et al., 2003). De acordo com o Instituto Brasileiro de Geografia e Estatística (IBCE), conforme o último censo demográfico, existiam no Brasil, em 2000, em números redondos, quatro milhões de domicílios com um só morador. O mesmo censo mostra que os casamentos estão ocorrendo em menor número relativo e com idade maior dos nubentes, ao passo que as separações formais (divórcios) ocorrem mais cedo e em maior quantidade relativa. Como tudo isso afeta o número e a caracterização de domicílios com um só morador em diferentes cidades da Federação? Quais são as principais tendências para grupos de pessoas que vivem sozinhas?

Para responder a essas questões, fez-se um estudo a partir de microdados dos últimos quatro censos gerais realizados no país pelo IBGE. Os dados analisados, portanto, provêm dos censos demográficos brasileiros de 1970, 1980, 1991 e 2000. O foco recaiu sobre as oito maiores cidades por população: São Paulo (SP), Rio de Janeiro (RJ), Salvador (BA), Belo Horizonte $(\mathrm{MG})$, Fortaleza (CE), Curitiba (PR), Recife (PE) e Porto Alegre (RS). O período contemplado foi de trinta anos e, por causa de sua extensão, diversas adequações entre maneiras de levantar dados tiveram de ser feitas. Dessa forma, foi possível construir um banco de dados com as seguintes variáveis sociodemográficas de segmentação de mercado: sexo, idade, renda, alfabetização, aposentadoria e condição do domicílio. 
De forma introdutória, pode-se afirmar que a divergência entre o crescimento da população e do número de habitações, ao que parece, ficará cada vez mais pronunciada nos próximos anos. A população total das oito cidades pesquisadas cresceu à taxa anual de 1,85\% entre 1970 e 2000, enquanto o número de domicílios se elevou à taxa anual de 2,94\%. O segmento de consumidores que vivem sozinhos, no entanto, cresceu 5,13\% por ano no mesmo período, o que supera o índice de crescimento da população como um todo. Em consequência, a participação deste segmento está aumentando: em 1970, era de 5,97\% da população das oito cidades; em 1980, de 7,43\%; em 1991, de 8,60\%; e em 2000, chegou ao patamar de 11,22\%. O estudo mostra que o segmento se compõe de uma multiplicidade de subsegmentos, em função das variáveis sociodemográficas - sexo, idade, renda, aposentadoria, alfabetização e condição dos domicílios - além do fato de os subsegmentos se distribuírem de maneira diversa entre as cidades estudadas.

De acordo com esse panorama, torna-se essencial considerar o aumento do número de pessoas que vivem sozinhas e também sua caracterização sociodemográfica quando se abordam questões ligadas a consumo, produção de bens e serviços, administração pública, organização do espaço urbano e meio ambiente. Acredita-se que as mudanças no número de habitantes por domicílio causarão mudanças significativas em processos produtivos, hábitos de consumo, estruturas urbanas e tratamento dos resíduos industriais e residenciais.

Como o empresariado tem se dirigido ao segmento de mercado dos que vivem sós? Desde algum tempo, companhias vêm fracionando ou reduzindo porções e embalagens, além de dedicar-se a criar eletrodomésticos e imóveis e oferecer viagens e uma gama de outros "sonhos de consumo" destinados à porção abastada deste segmento. Porém, o estudo demonstra que nem só alto poder aquisitivo e crescimento acelerado caracterizam este grupo.

É verdade que o segmento tem crescido a taxas superiores às aferidas para a população como um todo. Todavia, no tocante a alto poder aquisitivo, a realidade não aponta para a existência de um segmento monolítico em sua composição; ela aponta para um segmento multifacetado, formado por diversos componentes, dos quais apenas alguns ostentam alto padrão de vida. O que mais chama atenção, inclusive, em estudo recente sobre as pessoas que moram sós no Brasil, é a heterogeneidade entre os subsegmentos que formam este segmento.

Este trabalho apresenta, primeiramente, uma fundamentação teórica a respeito da segmentação de mercados. O conceito de segmentação de mercado é importante porque sugere que o mercado não é um todo homogêneo; ele se compõe de vários grupos de consumidores, que apresentam características e perfis diferentes. Sendo assim, um segmento de mercado constitui-se de um agrupamento de indivíduos que possuem características similares entre si. (TOLEDO, 1972; WEINSTEIN, 1995). Em seguida, o trabalho organiza informações provenientes de literatura que explora questões sobre o segmento da população que vive só, disponibilizando um primeiro panorama da sua condição. A próxima etapa é composta pelo registro dos resultados da pesquisa, apontando as tendências identificadas e terminando por destacar as conclusões, limitações e sugestões para outros estudos.

\section{EVOLUÇÃO DO CONCEITO DE SEGMENTAÇÃO DE MERCADO}

Primeiramente, faz-se necessário definir o que é mercado. Czinkota, Kotabe e Mercer (1997) definem mercado como o lugar onde os bens e serviços são vendidos e distribuídos, e os lucros, gerados. Para os autores, ele pode ser delimitado também em termos geográficos e demográficos, porém é sempre determinado com base em consumidores. Compõe-se por to- 
dos os consumidores potenciais que compartilham necessidades e desejos e estão dispostos a satisfazê-los por meio de bens ou serviços. Para Kotler e Armstrong (2007, p. 6), o mercado "é o conjunto de compradores reais e potenciais de um produto. Esses compradores compartilham de um desejo ou uma necessidade específicos que podem ser satisfeitos por meio de trocas e relacionamentos". Sendo assim, o mercado se compõe por grupos de consumidores heterogêneos entre cada grupo e homogêneos internamente. Cada um destes grupos de indivíduos constitui um segmento de mercado. (CZINKOTA; KOTABE; MERCER, 1997). Para Boone e Kurtz (1998), a segmentação de mercado é um processo que requer a identificação dos fatores que afetam as decisões de compra e, consequentemente, os grupos consumidores.

A segmentação de mercado surgiu de um conceito acadêmico que caminhou para uma estratégia empregada no mundo real. Segundo Weinstein (1995), segmentar um mercado é o mesmo que dividir os consumidores potenciais, procurando agrupá-los com base em características similares. A ideia é compor um segmento de mercado que, possivelmente, exibirá comportamento de compra parecido entre seus membros. O autor ainda destaca que "o objetivo da pesquisa de segmentação é analisar mercados, encontrar nichos e oportunidades e capitalizar por meio de uma posição competitiva superior". (WEINSTEIN, 1995, p. 18).

O conceito de segmentação de mercado foi reconhecido, primeiramente, por Wendell R. Smith em artigo de 1956 intitulado Product Differentiation and Market Segmentation as Alternative Marketing Strategies. Para Smith (1956), a segmentação de mercado consiste em se considerar um mercado heterogêneo (assim chamado quando apresenta demandas divergentes) a reunião de um número de mercados homogêneos menores (homogêneos internamente, ou seja, os indivíduos que compõem aquele mercado apresentam demandas similares). Esta divisão é consequência de preferências diferenciadas de produtos.

A partir dessa definição, três tipos de segmentação ganharam impulso. A primeira foi a segmentação geográfica. Pequenas manufaturas que desejavam limitar seus investimentos ou que possuíam canais de distribuição pouco abrangentes para cobrir todo o país acabaram segmentando ou dividindo o mercado americano e vendendo seus produtos em apenas algumas áreas geográficas específicas. Este tipo de segmentação se tornou popular para pequenas manufaturas, varejistas, bancos e prestadores de serviços. (SMITH, 1956).

Como as marcas, cada vez mais, tornavam-se nacionais nos Estados Unidos e precisavam que a mídia tivesse o mesmo alcance, criou-se a segunda forma de segmentação - a segmentação demográfica. Este tipo de segmentação emprega variáveis como idade, sexo, renda, ocupação, raça, entre outras.

O terceiro tipo de segmentação que ganhou impulso foi o comportamental, que divide os consumidores em grupos baseados em seu comportamento de consumo. A segmentação comportamental foi dividida, por sua vez, em função da intensidade de uso de um produto, pelos padrões de fidelidade à marca, pelo grau de substituição de uma marca ou produto e pela ocasião de uso ou situação de consumo.

Haley (1985) destaca que há confusão quanto à origem do termo "psicográfico". Informações comportamentais, dados demográficos, pensamentos relativos a benefícios, características de personalidade e características de estilo de vida vão além dos padrões demográficos. Deste modo, achou-se conveniente buscar, na Psicologia, a base para estas análises. Daí surgia o termo "psicográfico", que, originalmente, funcionava para cobrir a amplitude das questões da mente, excluindo-se as abordadas pela segmentação demográfica e comportamental. Este termo abrange o universo de benefícios, problemas, estilo de vida, dados de personalidade, valores e percepções. 
Dessa maneira, a divisão geográfica e demográfica constitui a primeira base para se definir as características comuns entre indivíduos e colocá-los em grupos, para segmentar mercados. O estudo da demografia estabelece uma aproximação com o comportamento do consumidor ao analisar a sua idade, sexo, nível social etc. As análises de tendências demográficas associadas a características econômicas, como renda ou capacidade de compra, podem ser empregadas na previsão de demanda e consumo ao longo do tempo. Podem ainda ajudar no desenvolvimento de produtos, marcas, na distribuição de mídia e na comunicação. (HALEY, 1985; LAMBIN, 1989, 2000; WEINSTEIN, 1995; KOTLER, 1995; KOTLER; ARMSTRONG, 2007; CZINKOTA; KOTABE; MERCER, 1997; BOONE; KURTZ, 1998; BLACKWELL; MINIARD; ENGEL, 2001).

\section{O SEGMENTO DA POPULAÇÃO QUE VIVE SOZINHA}

Anos atrás, iniciaram-se alterações, nas estruturas sociais, que têm impulsionado o crescimento da população que vive sozinha. É nas metrópoles que o fenômeno se verifica mais intensamente, segundo Liu et al. (2003). O estudo destes autores foi o primeiro, em profundidade, a destacar o impacto das pessoas que moram sozinhas sobre o meio ambiente. O estudo revela que 76 países apresentam as maiores taxas de participação deste segmento em relação à população total e que o Brasil faz parte dos dez primeiros países.

Segundo Liu et al. (2003), o tamanho e a taxa de crescimento da população sempre são considerados importantes determinantes dos danos ao meio-ambiente, contudo a dinâmica domiciliar é, usualmente, negligenciada. As estatísticas demográficas podem mascarar mudanças substanciais no tamanho e no número dos domicílios e seus efeitos. Mesmo quando o tamanho da população declina, o número de domicílios pode crescer substancialmente. Este rápido crescimento resulta em um maior consumo de recursos. A diferença entre a taxa de crescimento da população e a de domicílios sugere que é crucial considerar o aumento do número de domicílios. As causas atribuídas para a redução do número de indivíduos por domicílio estão ligadas à redução da taxa de fertilidade, ao aumento da renda per capita, ao aumento das taxas de divórcio, ao envelhecimento da população e ao declínio da frequência de famílias compostas por parentes de várias gerações.

Segundo o Instituto de Pesquisas Econômicas Aplicadas (IPEA, 2005), muitos estudos apontam um aumento do individualismo habitacional, no mundo, a partir do Pós-Segunda Guerra Mundial, com uma intensificação a partir dos anos 80, devido ao surgimento de uma espécie de ideologia individualista. Esta ideologia baseia-se em um novo estilo de vida, que se instaura de forma crescente e associa-se a novas situações de famílias, aumento de separações, não casamentos e pessoas que têm relações maritais estáveis, mas que vivem em casas separadas.

Vive-se hoje a transição de valores familiares. Desde 1960, as taxas de divórcio vêm aumentando, e a taxa de natalidade, decrescendo. As mudanças são significativas desde a Revolução Industrial, mais de duzentos anos atrás. Na era Pré-Industrial, era norma a família numerosa, que garantia estabilidade econômica e representava bem estar. O domicílio era a unidade primária de produção; trabalho e vida familiar estavam integrados; e trabalhadores domésticos, juntamente com amigos e parentes, compunham a unidade domiciliar. Com o advento da sociedade industrial, a família mudou e foi se tornando menor. A família extensa, por exemplo, perdeu lugar para o núcleo familiar. As normas para as pessoas de cada sexo eram rigorosamente demarcadas: os homens trabalhavam fora e as mulheres ficavam em casa e cuidavam dos filhos. Este padrão familiar foi a base para aquele que surgiu após 1945, caracterizado pelo paternalismo do empregador, crescimento dos padrões de vida e trabalho e de seguran- 
ça. Hoje, presencia-se o encolhimento das estruturas familiares e o crescimento de um segmento composto por indivíduos que vivem sozinhos. (WILKINSON, 1999).

No Brasil, mais de 4,6 milhões de domicílios surgiram entre 1991 e 2000, em função da redução do número de pessoas por domicílio. (LIU et al., 2003). Em 2000, existiam, no Brasil, quatro milhões de domicílios com uma só pessoa, o que passou a ser alvo de algumas indústrias de alimentos, bebidas e produtos de higiene pessoal e de limpeza doméstica. O censo do IBGE correspondente a esta data revela que as pessoas estão casando menos e com mais idade, principalmente nos estratos mais ricos da população, e as separações formais (divórcios) estão acontecendo mais cedo e em número maior a cada ano pesquisado.

O Brasil dispõe de poucos e incompletos estudos sobre o tema. Por este motivo, o estudo do fenômeno requer o levantamento e a análise de dados, para que se possa identificar e compreender suas características. A partir dos dados censitários disponíveis, é possível gerar uma documentação para ser empregada em setores públicos, industriais, varejistas e em questões relacionadas ao meio ambiente.

\section{METODOLOGIA EMPREGADA NO ESTUDO}

Para elaborar a pesquisa, recorreu-se à análise de dados secundários originários dos censos brasileiros de 1970, 1980, 1991 e 2000, cobrindo oito capitais de estados: São Paulo, Rio de Janeiro, Salvador, Belo Horizonte, Fortaleza, Curitiba, Recife e Porto Alegre. ${ }^{3}$ Os dados colhidos disponibilizam informações de caráter geodemográfico e socioeconômico a respeito dos indivíduos que habitam os domicílios pesquisados pelos censos brasileiros. Estes dados constituem a base para a investigação acerca das características que podem classificar e descrever o segmento dos indivíduos que vivem sozinhos.

O censo é uma pesquisa de caráter geodemográfico que se compõe de um conjunto de dados estatísticos dos habitantes de uma cidade, província, estado ou nação. O censo é a principal fonte de dados sobre a situação de vida de uma população. A mensuração agregada de dados geodemográficos tem como objetivo identificar os grupos ou segmentos que apresentam características sociais, econômicas e demográficas semelhantes. (CURRY, 1993).

O primeiro cuidado que o estudo exigiu foi a análise minuciosa da organização dos bancos de dados censitários de 1970, 1980, 1991 e 2000. Estes bancos de dados são compostos por uma amostra probabilística sistemática que corresponde a $25 \%$ da população total de cada cidade. São heterogêneos em seus esquemas de organização, na quantidade e nas características das variáveis que investigam, nas categorias que as compõem e nos conceitos que adotam. O procedimento adotado para o tratamento dos dados censitários foi, primeiramente, a definição do conjunto de variáveis comparáveis entre as quatro datas. Em seguida, essas variáveis foram ajustadas e padronizadas, compondo um novo banco de dados uniforme, e contendo os dados referentes às oito cidades a serem investigadas.

Calcularam-se as frequências, e utilizou-se a técnica Crosstabs. Empregou-se também a técnica de Análise de Conglomerados às variáveis de caracterização dos indivíduos que vivem sós, a qual permite segmentar elementos em grupos homogêneos internamente, heterogêneos entre si e mutuamente excludentes. Como resultado, identificaram-se os subsegmentos que compõem o segmento de indivíduos que vivem sozinhos e suas características. Os resultados obtidos foram avaliados e organizados procurando destacar as similaridades e divergências ao longo do tempo, como se resume a seguir.

\footnotetext{
3 As fontes dos dados dos censos demográficos estão registradas nas referências bibliográficas.
} 


\section{RESULTADOS}

\subsection{Cidades}

No início do levantamento, acreditava-se que haveria certa homogeneidade na composição do segmento, em todas as oito cidades pesquisadas; ou, então, que existiria alguma forma de regionalismo nas subdivisões do grupo de cidades. A primeira surpresa proporcionada pelo estudo deveu-se às diferenças marcantes entre as cidades e também à diferente evolução temporal das características do segmento em cada cidade. Também chama atenção o fato de as maiores taxas de crescimento do segmento não corresponderem às cidades que apresentam as maiores participações de domicílios habitados por uma única pessoa. Tal fato sugere que poderá haver mudanças na classificação das maiores cidades por número relativo de domicílios habitados por um único morador futuramente. Na sequência, relatam-se algumas das características mais notáveis das oito maiores capitais brasileiras, no que diz respeito aos consumidores que moram sós em domicílios particulares permanentes.

Curitiba, apesar de não figurar como a primeira cidade quando se trata de número, absoluto e relativo, de consumidores que vivem sós, apresentou altas taxas de crescimento anual, tanto para a parcela de aposentados quanto para a de não-aposentados. Nesta cidade, há menos aposentados do que não-aposentados, como é a regra geral para as oito capitais. Os aposentados compõem-se, predominantemente, de mulheres de 60 anos ou mais, alfabetizadas e com renda de até cinco ou de mais de 20 salários mínimos. A maior taxa de crescimento, no período focalizado, corresponde aos consumidores não-aposentados, grupo no qual se verificou, em 1970, 1980 e 2000, a preponderância de mulheres alfabetizadas. Apenas em 1991 a maioria de não-aposentados era formada por homens. Atualmente, os não-aposentados se concentram entre as faixas etárias compreendidas entre 20 e 59 anos, com faixas de renda de até cinco ou de mais de 20 salários mínimos.

Salvador aparece como a campeã em crescimento da parcela dos moradores solitários aposentados, sendo a capital com o maior percentual de domicílios habitados por uma única pessoa não-aposentada em 2000. Em 1970, o conjunto dos aposentados compunha-se, principalmente, de homens e, a partir de 1980, este cenário se alterou, com a predominância de mulheres. Vale destacar que, em 1980, 48,19\% das mulheres eram analfabetas, tinham 60 anos ou mais e renda entre meio e um salário mínimo. A partir de 1991, a parcela feminina passou à condição de alfabetizada e, em 2000, concentrou-se em mulheres de, pelo menos, 60 anos, alfabetizadas e com renda em duas faixas: uma entre três e cinco e outra superior a 20 salários mínimos. Na parcela de não-aposentados, havia predomínio de homens, distribuídos em diversas faixas etárias e de renda.

A capital a exibir a segunda maior taxa de participação de não-aposentados, em 2000, é Fortaleza, que, porém, aparece em penúltimo lugar quando se avalia a participação de domicílios com uma só pessoa em relação ao total. Os consumidores que ainda não haviam se aposentado pertenciam, principalmente, ao sexo masculino, tinham idade entre 30 e 39 anos, eram alfabetizados e apresentavam renda de até dois ou entre cinco e dez salários mínimos. Os aposentados, em 1970, concentravam-se na população masculina de 60 anos ou mais. A partir de 1980, esta composição se alterou, passando a haver predomínio da população feminina de 60 anos ou mais, alfabetizada e distribuída em faixas de renda de até três e entre cinco e dez salários mínimos. 
Belo Horizonte é cidade caracterizada pela predominância de mulheres aposentadas, com idade a partir de 60 anos, alfabetizadas e com faixas de renda distintas: uma de até dois e outra entre 15 e 20 salários mínimos. Os consumidores não-aposentados, por outro lado, são principalmente do sexo masculino, de idade entre 30 e 39 anos, alfabetizados e com renda em três faixas distintas: até dois, de cinco a dez e superior a 20 salários mínimos.

Recife destaca-se pelo predomínio de mulheres de 60 anos ou mais, alfabetizadas e com faixas de renda de até dois e entre cinco e dez salários mínimos no conjunto de consumidores que vivem sós e estão aposentados, para todo o intervalo de tempo analisado. A parcela de não-aposentados também se compunha, basicamente, de mulheres no período de $1970 \mathrm{a}$ 1980; depois, passou a haver predomínio masculino. A partir de 1991, a parcela de homens não-aposentados se concentrou na faixa etária entre 30 e 39 anos, alfabetizados e com renda de até dois ou de mais de 20 salários mínimos.

Porto Alegre figura como a cidade com maior participação de domicílios com apenas uma pessoa em relação ao total de domicílios, com 17,31\% em 2000. No segmento dos aposentados, prevalece a parcela do sexo feminino, fundamentalmente mulheres com mais de 50 anos, alfabetizadas e com renda nas faixas de até dois e de cinco a dez salários mínimos. A preponderância feminina também se dá para os não-aposentados em 1970, 1980 e 2000. Em 1991, no entanto, a maioria dos não-aposentados pertencia ao sexo masculino. As mulheres do grupo de não-aposentados, em 2000, distribuíam-se em diversas faixas etárias e de renda, o que destaca, mais uma vez, a heterogeneidade dos moradores solitários.

São Paulo é a maior capital estadual do Brasil em número de consumidores que vivem sozinhos. Os moradores solitários aposentados são, predominantemente, do sexo feminino, de 60 anos ou mais, alfabetizados e com rendimento nas faixas de renda que se situam entre um quarto e dez salários mínimos. Os não-aposentados, entretanto, pertencem, na maioria dos casos, ao sexo masculino, têm idade entre 30 e 49 anos, são alfabetizados e apresentam rendimento nas faixas de renda compreendidas entre cinco e 20 salários mínimos.

Por fim, no Rio de Janeiro - segunda maior cidade da Federação em número de pessoas que vivem sós -, verifica-se que, entre os consumidores aposentados, predominam mulheres de mais de 60 anos, alfabetizadas e distribuídas em diversas faixas de renda, que vão desde um quarto até mais de 20 salários mínimos. Entre 1970 e 1991, a parcela de não-aposentados compunha-se, predominantemente, de homens. Em 2000, constata-se equilíbrio na divisão entre os sexos. Na população feminina, destaca-se a parcela de idade superior a 50 anos, alfabetizada e com renda em duas faixas: uma de até dois e a outra de mais de 20 salários mínimos. Integram a parcela masculina indivíduos com idade entre 30 e 49 anos, alfabetizados e com três faixas de renda distintas: a primeira de até dois, a segunda entre cinco e dez e a última entre 10 e 15 salários mínimos.

\subsection{Tendências}

O que todas essas cidades têm em comum? Embora se perceba diversidade, é possível identificar linhas condutoras e tendências. A composição do conjunto de pessoas que vivem sozinhas apresentava participação crescente de aposentados até 1991. Naquele momento, atingiuse a máxima média geral, de 39,33\%, para as oito cidades consideradas. Em 2000, verificou-se queda para o nível de $29,74 \%$. Há possíveis motivos para este comportamento, como o aumento da expectativa de vida, inicialmente, e, depois, a necessidade de continuar trabalhando para 
viabilizar a subsistência, ou seja, explicações socioeconômicas. Em 2000, Rio de Janeiro e Porto Alegre exibiam as maiores participações de aposentados: $33,67 \%$ e 32,39\%, respectivamente (Tabela 1).

Tabela 1 - Características dos domicílios habitados por um único morador

\begin{tabular}{|c|c|c|c|c|c|c|c|}
\hline & $\begin{array}{c}\text { Domicílios } \\
\text { com um só } \\
\text { morador } \\
2000\end{array}$ & $\begin{array}{c}\text { Participação } \\
\text { no total de } \\
\text { domicílios } \\
2000 \\
(\%)\end{array}$ & $\begin{array}{c}\text { Taxa anual de } \\
\text { crescimento } \\
\text { entre } 1970 \mathrm{e} \\
2000 \\
(\% \text { ao ano })\end{array}$ & $\begin{array}{c}\text { Homens } \\
\text { e } \\
\text { Mulheres } \\
\mathbf{2 0 0 0} \\
(\%)\end{array}$ & $\begin{array}{c}\text { Aposentados } \\
\text { e } \\
\text { não } \\
\text { aposentados } \\
2000(\%)\end{array}$ & $\begin{array}{c}\text { Até } 29 \text { anos } \\
30 \text { a } 59 \text { anos } \\
60 \text { ou } \\
\text { mais anos } \\
\text { de idade } \\
2000(\%)\end{array}$ & $\begin{array}{c}\text { Até } 5, \\
\text { entre } 5 \text { e } 10 \\
\text { acima de } \\
10 \text { salários } \\
\text { mínimos } \\
2000(\%)\end{array}$ \\
\hline São Paulo & 308121 & 10,32 & 5,34 & $\begin{array}{l}40,47 \\
59,53\end{array}$ & $\begin{array}{l}29,19 \\
70,81\end{array}$ & $\begin{array}{l}13,47 \\
49,65 \\
36,88\end{array}$ & $\begin{array}{l}49,15 \\
18,83 \\
24,38\end{array}$ \\
\hline Rio de Janeiro & 242000 & 13,43 & 3,94 & $\begin{array}{l}39,89 \\
60,11\end{array}$ & $\begin{array}{l}33,67 \\
66,33\end{array}$ & $\begin{array}{c}8,40 \\
47,14 \\
44,46\end{array}$ & $\begin{array}{l}49,77 \\
19,69 \\
23,95\end{array}$ \\
\hline Porto Alegre & 76253 & 17,31 & 6,60 & $\begin{array}{l}37,35 \\
62,65\end{array}$ & $\begin{array}{l}32,39 \\
67,61\end{array}$ & $\begin{array}{l}12,96 \\
51,68 \\
35,36\end{array}$ & $\begin{array}{l}46,72 \\
22,18 \\
27,21\end{array}$ \\
\hline Salvador & 69707 & 10,70 & 6,17 & $\begin{array}{l}54,42 \\
45,58\end{array}$ & $\begin{array}{l}20,87 \\
79,13\end{array}$ & $\begin{array}{l}16,85 \\
58,78 \\
24,37\end{array}$ & $\begin{array}{l}62,79 \\
12,51 \\
13,11\end{array}$ \\
\hline Belo Horizonte & 67975 & 10,82 & 5,77 & $\begin{array}{l}44,17 \\
55,83\end{array}$ & $\begin{array}{l}29,47 \\
70,53\end{array}$ & $\begin{array}{l}13,58 \\
55,53 \\
30,89\end{array}$ & $\begin{array}{l}52,05 \\
18,86 \\
24,29\end{array}$ \\
\hline Curitiba & 52516 & 11,15 & 8,41 & $\begin{array}{l}38,83 \\
61,17\end{array}$ & $\begin{array}{l}28,66 \\
71,34\end{array}$ & $\begin{array}{l}16,45 \\
49,89 \\
33,66\end{array}$ & $\begin{array}{l}48,30 \\
21,30 \\
25,13\end{array}$ \\
\hline Fortaleza & 34047 & 6,47 & 6,32 & $\begin{array}{l}50,50 \\
49,50\end{array}$ & $\begin{array}{l}22,25 \\
77,75\end{array}$ & $\begin{array}{l}17,38 \\
55,68 \\
26,94\end{array}$ & $\begin{array}{l}66,57 \\
10,88 \\
12,19\end{array}$ \\
\hline Recife & 33806 & 8,99 & 3,76 & $\begin{array}{l}43,63 \\
56,37\end{array}$ & $\begin{array}{l}28,79 \\
71,21\end{array}$ & $\begin{array}{l}12,72 \\
52,23 \\
35,05\end{array}$ & $\begin{array}{l}60,47 \\
12,74 \\
16,21\end{array}$ \\
\hline
\end{tabular}

Fonte: elaborada pelos autores.

Na análise da variável sexo, constata-se que, em 1970, a participação masculina representava menos da metade da população apenas nas cidades de Curitiba, Recife e Porto Alegre. Somente Salvador, de 1970 até 2000, compunha-se de maioria masculina, com cerca de 55\% de participação em todo o período. A partir de 2000, apenas Fortaleza apresenta composição equitativa entre homens e mulheres. Nas demais cidades, a população feminina é dominante e supera os $55 \%$ do total, percentual que é condizente com uma maior longevidade da população feminina em comparação à masculina.

O primeiro ponto a se considerar quando se analisa a composição de uma população em função da distribuição em faixas etárias refere-se ao modo como estas faixas se alteram ao longo do tempo, principalmente em decorrência das mudanças de taxa de natalidade, de mortalidade ou de expectativa de vida. Constata-se que as pessoas que vivem sozinhas se concentram especialmente nas faixas etárias superiores a 30 anos e têm maior presença a partir de 60 anos, limite a partir do qual situa-se mais de um terço desta população. As pessoas com idades de 30 a 39, de 40 a 49 e de 50 a 59 anos perfazem, juntas, metade do segmento e se encontram representadas de maneira muito semelhante. A faixa etária de 20 a 29 anos apresenta comportamento declinante, tendo atingido $12,61 \%$ do total em 2000, contra 18,07\% em 1970. A redução dessa faixa etária continuará no futuro? O que representará o envelhecimento da popula- 
ção que vive sozinha para os negócios e também para as políticas públicas? Trata-se, realmente, de uma tendência?

A inflação das faixas etárias mais altas em detrimento das mais baixas indica, sem dúvida, a tendência ao envelhecimento do segmento. Possivelmente, a sociedade se deparará com a formação de uma "bolha" composta por indivíduos com idade a partir de 60 anos. Pode-se denominar este fenômeno de "bolha" pelo fato de que ele acabará gerando expressivo aumento do grupo em um primeiro momento, dirigindo a participação para um ponto de concentração. Em um segundo momento, o efeito se atenuará, em função da ruptura causada pela inexorável morte de grande parte de seus componentes.

A análise também aponta que ainda há analfabetos em todas as cidades. Em 2000, Salvador tinha $11,20 \%$ e Fortaleza, $17,66 \%$ de indivíduos vivendo sós e analfabetos - a maior incidência de analfabetos desde 1970 (46,56\% do total da população naquele ano). No último censo demográfico, a participação média de analfabetos para as oito cidades estava em $7,72 \%$ do total do segmento. As cidades de Curitiba e Porto Alegre exibem as menores taxas de participação de analfabetos: 5,28\% e 4,02\% dos que moram sós, em 2000, respectivamente. Embora com redução, a participação de analfabetos no segmento ainda representa fator ponderável para os planos empresariais e governamentais.

A composição do segmento, segundo a renda, evidencia a polarização das faixas dominantes - de um lado, a baixa renda; de outro, a mais elevada. Os indivíduos com renda entre as faixas de meio até dez salários mínimos apresentam participação decrescente no total do segmento. No caso de rendas superiores (de dez a 15, de 15 a 20 e de mais de 20 salários mínimos), os números mostram crescimento. Ainda hoje, porém, há significativa participação de indivíduos sem rendimento, cabendo destacar Salvador, Fortaleza e Recife (superior a 10\%). As menores participações ocorrem em Belo Horizonte, Curitiba e Porto Alegre (inferior a 5,5\%). A existência de tal polaridade de poder aquisitivo tem relevância para as tomadas de decisão nas organizações, privadas e governamentais. A existência de dois grupos distintos de consumidores que vivem sós e apresentam distintas inclinações para o consumo e para o acesso a serviços levará, certamente, a estratégias específicas.

Por fim, quando se avalia a condição dos domicílios habitados pelo segmento em 2000, verifica-se que, na maioria, trata-se de imóveis próprios (média geral para as oito cidades de $66,95 \%$ ) ou alugados (24,99\%). Outra vez uma dicotomia que exigirá estratégias específicas, das empresas e do governo.

\section{CONSIDERAÇÕES FINAIS}

Atender às necessidades e exigências do segmento composto por consumidores que vivem sozinhos é, potencialmente, trabalhar com mais de $10 \%$ do total da população brasileira, o que deve ser expressivo para a maioria das empresas e não pode ser desconsiderado pelas diversas esferas governamentais. Este percentual aponta para a necessidade de se dar atenção às implicações do fenômeno para o planejamento empresarial, para os planos urbanos, para a administração pública e para a ecologia. É importante também que empresários e governantes não percam de vista que o segmento abriga grupos com características muito diferentes em termos de renda, idade, alfabetização, condição de aposentadoria e residência. Às vezes, essas condições socioeconômicas são até mesmo opostas. 
O aumento desse segmento, associado à sua diversidade intrínseca, causará significativo impacto em processos produtivos, hábitos de consumo, necessidade de equipamentos urbanos e de tratamento de resíduos residenciais e industriais. O que este trabalho ambiciona é contribuir para a avaliação destes impactos e do potencial de negócios representado pelo correto reconhecimento da diversidade do segmento.

Como já ressaltado, o estudo foi desenvolvido com base em dados censitários originais dos censos demográficos de 1970, 1980, 1991 e 2000 do IBGE. Em função da própria escassez de trabalhos sobre indivíduos que vivem sós, deve-se atentar para as seguintes restrições: é apenas a partir de 1970 que as informações estão registradas em forma de banco de dados informatizado; há ausência de padronização dos dados disponibilizados nos censos brasileiros; e o estudo restringiu-se à análise de oito capitais de estados brasileiros.

O trabalho gerou indagações a respeito dos indivíduos que vivem sozinhos, em decorrência da análise dos dados empregados, da metodologia de pesquisa adotada e dos resultados encontrados. Tudo isso sugere estudos futuros, focalizando, por exemplo, a evolução do segmento de pessoas que vivem sozinhas em outras cidades brasileiras, as análises anteriores a 1970 e uma pesquisa a respeito do estilo de vida e do comportamento de consumo. Estas são algumas possibilidades de estudos que este tema sugere. A análise dos dados e os resultados registrados neste estudo podem ainda produzir outras questões, suposições e possibilidades de pesquisas e trabalhos.

\section{REFERÊNCIAS BIBLIOGRÁFICAS}

BLACKWELL, R. D.; MINIARD, P. W.; ENGEL, J. F. Consumer behavior. 9. ed. South-Western: Thomson Learning, 2001.

BOONE, L. E.; KURTZ, D. L. Marketing contemporâneo. 8. ed. Rio de Janeiro: Livros Técnicos e Científicos, 1998.

CENSO DEMOGRÁFICO BRASIL. VIII Recenseamento Geral 1970. Série Nacional, v, 1. Rio de Janeiro: IBGE, 1973. CD-ROM.

. Microdados 1970 - Amostra: Regiões Centro-Oeste e Sul. Rio de Janeiro: IBGE, 1973. CD-ROM.

. Microdados 1970 - Amostra: Região Sudeste. Rio de Janeiro: IBGE, 2003. CD-ROM.

Microdados 1970 - Amostra: Regiões Norte e Nordeste. Rio de Janeiro: IBGE, 1973. CD-ROM.

Microdados 1970 - Amostra: São Paulo. Rio de Janeiro: IBGE, 1973. CD-ROM.

. IX Recenseamento Geral 1980. Dados Gerais, Migração, Instrução, Fecundidade, Mortalidade. Rio de Janeiro: IBGE, 1983. CD-ROM.
. IX Recenseamento Geral 1980. Dados Gerais, Famílias e Domicílios. Rio de Janeiro: IBGE, 1983. CD-ROM.

. Microdados 1980 - Amostra: CD-ROM n. 7. Rio de Janeiro: IBGE, 1983. CD-ROM.

. Microdados 1980 - Amostra: Rio de Janeiro

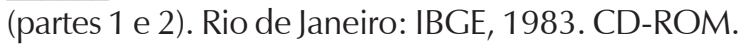

. Microdados 1980 - Amostra: Minas Gerais (parte 1). Rio de Janeiro: IBGE, 1983. CD-ROM.

. Microdados 1980 - Amostra: Minas Gerais (parte 2$)$. Rio de Janeiro: IBGE, 1983. CD-ROM.

Microdados 1980 - Amostra: São Paulo $\overline{\text { (partes }} 1$ e 2, a e b). Rio de Janeiro: IBGE, 1983. CD-ROM.

Microdados 1980 - Amostra: São Paulo (parte 3). Rio de Janeiro: IBGE, 1983. CD-ROM.

. Microdados 1980 - Amostra: São Paulo (parte 4). Rio de Janeiro: IBGE, 1983. CD-ROM.

Microdados 1980 - Amostra: Rio Grande

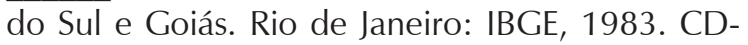
ROM. 
Microdados 1980 - Amostra: Pernambuco, Sergipe, Espírito Santo, Mato Grosso do Sul e Mato Grosso. Rio de Janeiro: IBGE, 1983. CD-ROM.

- Microdados 1980 - Amostra: Ceará, Rio Grande do Norte, Paraíba e Alagoas. Rio de Janeiro: IBGE, 1983. CD-ROM.

. Microdados 1980 - Amostra: Rondônia, Acre, Amazonas, Roraima, Pará, Amapá, Fernandi de Noronha, Maranhão e Piauí. Rio de Janeiro: IBGE, 1983. CD-ROM.

- Microdados 1980 - Amostra: Região Nordeste 4 - Bahia. Rio de Janeiro: IBGE, 2003. CDROM.

Censo Demográfico 1991 - Famílias e Domicílios - Resultados da amostra n. 1. Rio de Janeiro: IBGE, 1996. CD-ROM.

. Censo Demográfico 1991 - Migração Resultados da amostra n. 1. Rio de Janeiro: IBGE, 1996. CD-ROM.

Microdados 1991 - Amostra: Região Sudeste 3 - São Paulo (parte 1 - Região Metropolitana). Rio de Janeiro: IBGE, 2003. CD-ROM.

. Microdados 1991 - Amostra: Região Sudeste 4 - São Paulo (parte 2 - Região Metropolitana). Rio de Janeiro: IBGE, 2003. CD-ROM.

. Microdados 1991 - Amostra: São Paulo (excluindo-se a Região Metropolitana). Rio de Janeiro: IBGE, 1996. CD-ROM.

- Microdados 1991 - Amostra: São Paulo (meso-região de 9 a 13 e microrregião de 55 a 56 e 61a 63). Rio de Janeiro: IBGE, 1996. CD-ROM.

Microdados 1991 - Amostra: Rio de Janeiro. Rio de Janeiro: IBGE, 1996. CD-ROM.

- Microdados 1991 - Amostra: Rio Grande do Norte, Paraíba, Pernambuco e Alagoas. Rio de Janeiro: IBGE, 1996. CD-ROM.

. Microdados 1991 - Amostra: Maranhão, Piauí e Ceará. Rio de Janeiro: IBGE, 1996. CD-ROM.

Microdados 1991 - Amostra: Minas Gerais e Espírito Santo. Rio de Janeiro: IBGE, 1996. CDROM.
- Microdados 1991 - Amostra: Rio Grande do Sul. Rio de Janeiro: IBGE, 1996. CD-ROM.

Microdados 1991 - Amostra: Sergipe e Bahia. Rio de Janeiro: IBGE, 1996. CD-ROM.

. Microdados 1991 - Amostra: Paraná e Santa Catarina. Rio de Janeiro: IBGE, 1996. CD-ROM.

Microdados 1991 - Amostra: Região Nordeste 1 - Maranhão, Piauí, Ceará, Rio Grande do Norte e Paraíba. Rio de Janeiro: IBGE, 2003. CDROM.

Microdados 1991 - Amostra: Região Nordeste 3 - Bahia. Rio de Janeiro: IBGE, 2003. CD-ROM.

. Microdados 1991 - Amostra: Pernambuco, Alagoas e Sergipe. Rio de Janeiro: IBGE, 2003. CDROM.

Censo Demográfico 2000 - Características da População e dos Domicílios - Resultados do Universo. Rio de Janeiro: IBGE, 2001. CD-ROM.

. Censo Demográfico 2000 - Trabalho e Rendimento - Resultados da Amostra. Rio de Janeiro: IBGE, 2003. CD-ROM.

. Censo Demográfico 2000 - Migração e Deslocamento - Resultados da Amostra. Rio de Janeiro: IBGE, 2003. CD-ROM.

Censo Demográfico 2000 - Famílias e Domicílios - Resultados da Amostra. Rio de Janeiro: IBGE, 2003. CD-ROM.

- Microdados 2000 - Amostra: Rio de Janeiro. Rio de Janeiro: IBGE, 2003. CD-ROM.

. Microdados 2000 - Amostra: v. 3 - Paraíba e Pernambuco. Rio de Janeiro: IBGE, 2003. CDROM.

. Microdados 2000 - Amostra: v. 4 - Alagoas, Ceará e Sergipe. Rio de Janeiro: IBGE, 2003. CDROM.

. Microdados 2000 - Amostra: v. 5 - Bahia. Rio de Janeiro: IBGE, 2003. CD-ROM.

. Microdados 2000 - Amostra: v. 9 - Minas Gerais (parte 2). Rio de Janeiro: IBGE, 2003. CDROM. 
Microdados 2000 - Amostra: v. 10 - São Paulo 1/3 - São Paulo (capital), Guarulhos e Campinas. Rio de Janeiro: IBGE, 2003. CD-ROM.

Microdados 2000 - Amostra: v. 13 - Paraná. Rio de Janeiro: IBGE, 2003. CD-ROM.

Microdados 2000 - Amostra: v. 15 - Rio Grande do Sul. Rio de Janeiro: IBGE, 2003. CDROM.

CURRY, D. J. The new marketing research systems: how to use strategic database information for better marketing decisions. New York: John Wiley \& Sons, 1993.

CZINKOTA, M. R.; KOTABE, M.; MERCER, D. Marketing management: text and cases. Oxford: Blackwell Publishers, 1997.

HALEY, R. I. Developing effective communications strategy: a benefit segmentation approach. USA: Ronald Press Publication; John \& Sons, 1985.

IPEA. Instituto de Pesquisa Econômica Aplicada. Disponível em: <http://www.ipea.gov.br>. Acesso em: 23 fev. 2005.

KOTLER, P. Administração de marketing: análise, planejamento, implementação e controle. 4. ed. Tradução de Ailton Bomfim Brandão. São Paulo: Atlas, 1995.

KOTLER, P; ARMSTRONG, G. Princípios de marketing. 12. ed. Tradução de Cristina Yamagami. São Paulo: Pearson Prentice Hall, 2007.
LAMBIN, J. Le marketing strategique: fondements, méthodes et applications. 2. ed. Paris: McGrow-Hill, 1989.

LAMBIN, J. Marketing estratégico. 4. ed. Tradução de Domingos Silva. Portugal: McGraw-Hill, 2000.

LIU, J. et al. Effects of househoud dynamics on resouse consumption and biodiversity. Nature, USA, n. 421, p. 530-533, jan. 2003. Disponível em: <http://www.nature.com>. Acesso em: 9 abr. 2003.

SMITH, W. R. Product Differentiation and Market Segmentation as Alternative Marketing Strategies. Journal of Marketing, USA, v. 21, p. 3-8, July 1956.

TOLEDO, G. L. Segmentação de mercado e estratégia de marketing. 1972. 198f. Tese (Doutorado em Administração)-Faculdade de Economia, Administração e Contabilidade, Universidade de São Paulo, São Paulo, 1972.

WEINSTEIN, A. Segmentação de mercado. Tradução de Celso A. Rimoli. São Paulo: Atlas, 1995.

WILKINSON, H. Celebrate the new family. New Statesman, London, v. 128, n. 4.448. p. 21-23, Aug. 1999. Disponível em: <http://trial.ep.net.com>. Acesso em: 21 fev. 2005. 